\title{
Non-cooperative and cooperative solutions of government subsidy on public transportation
}

\author{
Hennie Husniah ${ }^{1, *}$, Udjiana S. Pasaribu², Yuza Z. Beta ${ }^{2}$, and Asep K. Supriatna ${ }^{3}$ \\ ${ }^{1}$ Engineering Department, Langlangbuana University, Bandung, Indonesia \\ ${ }^{2}$ Mathematics Department, Institut Teknologi Bandung, Bandung, Indonesia \\ ${ }^{3}$ Mathematics Department, Universitas Padjadjaran, Bandung, Indonesia
}

\begin{abstract}
The paper deals with two models of government subsidy given to a public transport operator: (i) the subsidy for buying bus from an appointed public transport manufacturer, and (ii) the subsidy for reimbursing reduced ticket price for passengers. The models are developed to determine the maximum profit for both the public transport operator and the manufacturer. Since we consider two parties - the public transport operator and the manufacturer of the bus, then we use game theoretical approach by considering non-cooperative and cooperative solutions. Furthermore, since the bus is repairable we consider virtual age to model the preventive maintenance and we consider minimal repair to model the corrective maintenance. We analyse both type of subsidy models and give some numerical examples which show the effects of different subsidies to the profit of operator and manufacturer. The result of the numerical examples indicates that reducing ticket price would give a higher profit both to the operator and the manufacturer.
\end{abstract}

\section{Introduction}

The exesive use of natural resources is becoming prevalent nowadays. It is reported that due to the overusing and over-consuming of this natural resources of the planet, future sustainability of the vital resources is questioned. The Living Planet reported that the human consumption of natural resources is far above the capability of the Earth to replenish the resources. It is more than $30 \%$ higher than the Earth can replenish each year. This undoubtly leads to deforestation, degraded soils, polluted air and water, and the collapse many commercial fisheries and the extinction other species (The Guardian, Oct 2008). The world mostly agrees that something needs to be done to resolve this problem. The UNDP agenda of 12th SDG's goal points out that in "[a]chieving economic growth and sustainable development requires that we urgently reduce our ecological footprint by changing the way we produce and consume goods and resources" (UNDP, 2017).

Some large parts of energy consumption have gone to the transportation sector. Unwanted consumption in transportation is due to severe traffic congestion. In many urban areas, severe traffic congestion has been blamed to cause air pollution. It is also regarded to hinder economic activity to some extent and wasting unnecessary energy consumption. According to Indonesia's transportation ministry report, vehicles contribute $70 \%$ as the source of air pollutant in Jakarta. In 2009 alone there were 9.9 million vehicles in Jakarta, which made the air pollutant in the city was getting worse. In order to reduce the traffic congestion, the Indonesian government has arranged a subsidy policy in public transportation sector. In general there should be an optimal subsidy scheme to reduce emissions in urban cities. Some methods for designing optimal subsidy scheme in complex urban areas are readily available (Qin and Zhang, 2015).

A subsidy is often defined as a form of financial aid or support extended to an economic sector aiming of promoting economic and social policy [1]. The economic sector could be an institution, bussiness, or individual; and the form of the subsidies could be direct, such as cash grants and interest-free loans, and could be indirect, such as tax breaks, insurance, low-interest loans, accelerated depreciation, rent rebates, and reimbursement $[2,3]$. A subsidy is given by a government to an economic sector or even to a public service institution whenever there is a foreseen benefits generated by the economic sector or the public service institution, directly or indirectly. The benefits might be in the form of economic benefit, health benefit, environmental benefit, or any other recognized benefits. The American Public Transportation Association explored the health impacts of public transportation and found six benefits compared to the use of individual vehicles, i.e. it can make the users are more active physically, it is safer than individual vehicles, it reduces stress, it keeps air cleaner, it saves money of the user, and it provides access to essential needs later in life (http://transloc.com/6-health-benefits-of-publictransportation/).

Considering the many benefits of public transportation, in 2016 the Indonesia's Transportation Ministry gave subsidy to one of public transport operator, i.e. Damri, by supplying buses in 11 big cities, that is

\footnotetext{
* Corresponding author: hennie.husniah@gmail.com
} 
Medan, Padang, Palembang, Bandar Lampung, Bandung, Yogyakarta, Surakarta, Surabaya, Denpasar, Mataram, and Makassar (liputan6.com, 2016). This has been done to reduce the use of private or individual vehicles as the transportation mode in the cities. The reduction of the use of private or individual vehicles is expected to reduce the severe level of traffic congestion.

An early literature in public transport research has shown that the lack of efficient pricing scheme has been blamed as one of the responsible factors causes the severe traffic congestion in urban areas (Jackson, 1975). Hence, other attempt to increase the number of passengers of the public transport is by making an efficient pricing scheme, e.g. by reducing the ticket of the transportation. The rationale is that a lower public transport ticket price will discourage the use of private and individual vehicles, and hence favouring the use of public transport (Parry and Small, 2009).

Levinson and King (2013) pointed out that subsidy should be considered two ways - capital subsidy and operating subsidy. They argued that these two are related, although different enough so that the two should be considered separately. Providing assets (such as giving new buses) is considered as the former form of subsidy while giving reimbursement of reduced ticket price to the operator is regarded as the later form of subsidy. Inline to this argument, the present paper deals with government subsidy model given to the Damri in the aim to increase the use of buses as the main mode of transportation. There are two subsidy models that will be studied, i.e. subsidy given to the Damri for buying buses and subsidy given to the Damri for reimbursing of reduced ticket price.

Considering a leader-follower relationship between the Damri and the manufacturer of the buses, we consider non-cooperative solution and cooperative solution in order to maximize profit. In this scheme, the Damri acts as the leader which has the first opportunity in devising policy to maximize profit. The Manufacturer, as a follower, maximizes profit based on the Damri's policy that has been chosen. This paper is organized as follows. Section 2 gives model formulation and section 3 gives solution and analyzes the model. Section 4 gives numerical example to see which model is better and finally conclude in section 5 .

\section{Mathematical Model}

The following notations will be used in the model formulation.

$q \quad$ : number of passengers per bus per year

$Q$ : total number of passengers per year

$n \quad$ : bus demand

$P M$ : Preventive Maintenance

$C M$ : Corrective Maintenance

$K$ : bus operating year

$N \quad$ : number of PM per bus

$\delta \quad:$ degree of repair

$\lambda_{0}(t)$ : failure rate without $\mathrm{PM}$

$\lambda(t)$ : failure rate after PM

$p \quad$ : ticket price per passenger

$\mathrm{Cm}$ : expected total cost of $\mathrm{CM}$
$C f:$ cost per $\mathrm{CM}$

$C p:$ expected total cost of PM

$\mathrm{Cr}$ : manufacture production cost

$\tau \quad:$ PM's period

$u \quad$ : subsidy amount per year

$w$ : bus price

$\Psi l$ : operator's profit

$\Psi h$ : manufacture's profit

$\Psi$ : total profit

To formulate the model we make the assumption that wholesale the bus purchase price is determined by the manufacturer and the ticket price is determined by the Damri. It is also assumed that every failure item of the bus only need minimal repair so that time between failures is negligible. In the following section we define operator revenue model, operator expenses model, the PM and CM maintenance models, and other related concepts needed in the subsequent sections.

\subsection{Operator Revenue Model}

In ceteris paribus condition the demand's law said that if the product price increase then the demand will decrease and if the product price decrease then the demand will increase. In this case, if the number of passengers per year is $q$ and ticket price is $p$, assuming a linear relationship will have a demand function

$$
q(p)=\gamma_{0}+\gamma_{1} p
$$

with $\gamma_{1}<0$ and $\gamma_{0}>0$.

The number of buses per year $(n)$ can be obtained by dividing $q$ with bus capacity $m$ so that $n=\frac{q(p)}{m} ; n, m>0$. If the Damri operates in $K$ years and the number of passengers per year constant, then the total number of passengers is

$$
Q(p, K)=q(p) \cdot K ; K>0
$$

The Damri's revenue, $R_{d}$, is obtained from total passengers multiplied by the ticket price

$$
R_{d}(p, K)=Q(p, K) \cdot p
$$

In this paper, we will use two government subsidy models. First, subsidy for buying bus from manufacturer and the second one is subsidy for reducing ticket price. For simplicity, we use the index 1 for the first model and the index 2 for the second model.

For the first model, the subsidy doesn't influence demand function so $q\left(p_{1}\right)=\gamma_{0}+\gamma_{1} p_{1}$. For the second model, the subsidy amount $u$ influences the demand function so $q\left(p_{2}, u\right)=\gamma_{0}+\gamma_{1} p_{2}+\gamma_{2} u$ where 
$u, \gamma_{2}>0$. Thus, based on equation (3) we have revenue function $R_{d}$ :

$$
R_{d}=\left\{\begin{array}{l}
\left(\gamma_{0}+\gamma_{1} p_{1}\right) p_{1} K \\
\left(\gamma_{0}+\gamma_{1} p_{2}+\gamma_{2} u\right) p_{2} K
\end{array} ;\right.
$$

The first row is for the 1st model and the second row is for the 2 nd model. The function of the number of buses for the 1st model and the 2nd model is respectively given by the first and the second row of the following formula:

$$
n=\left\{\begin{array}{l}
\frac{\left(\gamma_{0}+\gamma_{1} p_{1}\right)}{m}, \\
\frac{\left(\gamma_{0}+\gamma_{1} p_{2}+\gamma_{2} u\right)}{m} .
\end{array}\right.
$$

\subsection{Operator Expenses Model}

The main Damri's expenses are the costs of preventive maintenance (PM), the cost of corrective maintenance (CM), and the cost of purchasing the buses. The maintenance is purported to reduce failure intensity. In this paper, we will use the two parameter Weibull failure intensity function $\lambda_{0}(t)$ with the scale parameter $\alpha=\left(2 / \theta^{1 / 2}\right.$ and the shape parameter $\beta=2$. Thus, we have a linear failure function $\lambda_{0}(t)=\theta t ; \theta \geq 0$. The following subsections derive the cost functions for the PM and $\mathrm{CM}$ respectively.

\subsubsection{Preventive Maintenance Cost Model}

Let the public transport operator undertakes $N$ times PM in $K$-years period, then the time interval between two PMs, i.e. $\tau$ is formulated by $\tau=K /(N+1)$ years. According to Kijima-Type 1 model, PM turns the age of bus $t$ into a virtual age $v(t)<t$. Assumed that every PM has the same degree of repair $0 \leq \delta \leq 1$, where $\delta=1$ means a minimal repair and $\delta=0$ means a perfect repair (Hamidi et al., 2016). By refering to Fig. 1 in (Hamidi et al., 2016), a PM reduces the failure intensity function to $\lambda(t)<\lambda_{0}(t)$ and the normal age by $(1-\delta) \tau$. As a result the bus virtual age for $i \tau \leq t<(i+1) \tau$ is $v(t)=i \delta \tau+t-i \tau$. So, the failure intensity function of the bus will become

$$
\lambda(t)=\lambda_{0}(v(t))=\theta(i \delta \tau+t-i \tau) .
$$

If every cost PM is $C_{p}^{*}=a+(1-\delta) \tau b$ then total cost for $N$ times of PM is given by

$$
C_{p}=N a+N(1-\delta) \tau b=N a+\frac{N b K(1-\delta)}{(N+1)} .
$$

\subsubsection{Corrective Maintenance Cost Model}

While operating, bus may have failure at a random time. When failures occur, bus need to be repaired. Every failure is assumed minimally repaired so that the failure intensity just the same as that just before the failure happened. Without any PM, failure follows a NonHomogenous Poisson Process (NHPP) with failure intensity $\lambda_{0}(t)$ (Jaturonnatee, et al., 2006; Chang \& Lo, 2011). After PM, failure process in the interval $[i \tau,(i+1) \tau)$ , for $i=0,1,2, \ldots N$ still follows the NHPP with the intensity function $\lambda(t)=\lambda_{0}(v(t))$ (Kim et al., 2004). The expected total number of failure is

$$
\begin{aligned}
\sum_{i=0}^{N} \int_{i \tau}^{(1+i) \tau} \lambda_{0}(v(t)) d t & =\sum_{i=0}^{N} \int_{i \tau}^{(1+i) \tau} \theta(i \delta \tau+t-i \tau) d t \\
& =\frac{K^{2} \theta(N \delta+1)}{2(N+1)} .
\end{aligned}
$$

If the cost for a PM is $C_{f}$, then the expected total amount of PM for $K$-years operating time is

$$
C_{m}=\frac{C_{f} K^{2} \theta(N \delta+1)}{2(N+1)} \text {. }
$$

\subsubsection{Bus Purchase Price}

Another expense for the public transport operator (Damri) is the bus purchasing price $w$. For the first subsidy model the Damri has received government subsidy for purchasing the buses, so that the Damri needs only to pay $w_{1}<w$. However, for the second model the Damri needs to pay $w_{2}=w$.

\subsubsection{Operator Profit function}

The Profit function is the difference between the revenue (4) and the expenses for PM (6), CM (7), and bus purchasing price. Damri's profit function for first subsidy model is given by

$$
\begin{aligned}
\Psi_{d_{1}}\left(p_{1}, w_{1}, K, N, \delta\right)= & R_{d_{1}}\left(p_{1}, K\right)-\left(w_{1}+C_{p}+C_{m}\right) n_{1} \\
= & \left(\gamma_{0}+\gamma_{1} p_{1}\right) p_{1} K \\
& -\left(w_{1}+C_{p}+C_{m}\right) \frac{\left(\gamma_{0}+\gamma_{1} p_{1}\right)}{m},
\end{aligned}
$$

and for the second model is 


$$
\begin{aligned}
\Psi_{d_{2}}\left(p_{2}, w_{2}, K, u, N, \delta\right) & =R_{d_{2}}\left(p_{2}, K\right)-\left(w_{2}+C_{p}+C_{m}\right) n_{2} \\
& =\left(\gamma_{0}+\gamma_{1} p_{2}+\gamma_{2} u\right) K p_{2} \\
& -\left(w_{2}+C_{p}+C_{m}\right) \frac{\left(\gamma_{0}+\gamma_{1} p_{2}+\gamma_{2} u\right)}{m} .
\end{aligned}
$$

\subsubsection{Manufacturefr Profit function}

If the production cost for every is $c_{m}$ then manufacture's profit function for the first model is

$$
\begin{aligned}
\Psi_{m_{1}}\left(p_{1}, u, w_{1}, K\right) & =u K+\left(w_{1}-C_{r}\right) n \\
& =u K+\left(w_{1}-C_{r}\right) \frac{\left(\gamma_{0}+\gamma_{1} p_{1}\right)}{m},
\end{aligned}
$$

and for second model is

$$
\begin{aligned}
\Psi_{m_{2}}\left(p_{2}, w_{2}, u\right) & =\left(w_{2}-C_{r}\right) n \\
& =\left(w_{2}-C_{r}\right) \frac{\left(\gamma_{0}+\gamma_{1} p_{2}+\gamma_{2} u\right)}{m} .
\end{aligned}
$$

\section{The Optimal Solution}

\subsection{Non Cooperative Solution}

In the non-cooperative solution, manufacturer will act as a leader and makes a decision policy first. Damri will then act as a follower and make profit policy based on manufacturer's policy. In the first subsidy model, we determine ticket price $p_{1}$ that maximizes profit function (8) by differentiating $\frac{\partial \Psi_{d_{1}}}{\partial p_{1}}=0$ and $\frac{\partial^{2} \Psi_{d_{1}}}{\partial p_{1}^{2}}<0$, which yields in

$$
p_{1}=\frac{1}{2 m K}\left(w_{1}+C_{p}+C_{m}\right)-\frac{\gamma_{0}}{2 \gamma_{1}}
$$

We substitute (12) into (9) to obtain

$$
\begin{aligned}
\Psi_{m_{1}}\left(p_{1}, u, w_{1}, K\right) & =u K+\frac{\gamma_{1}}{2 m^{2} K}\left(w_{1}-C_{r}\right) \\
& \left(w_{1}+C_{p}+C_{m}+\frac{\gamma_{0} m K}{\gamma_{1}}\right) .
\end{aligned}
$$

To get manufacturer's maximum profit, we determine $w_{1}$ so that $\frac{\partial \Psi_{w_{1}}}{\partial p_{1}}=0$ and $\frac{\partial^{2} \Psi_{w_{1}}}{\partial p_{1}^{2}}<0$, which yields in
$w_{1}=\frac{1}{2}\left(C_{r}-C_{p}-C_{m}-\frac{\gamma_{0} m K}{\gamma_{1}}\right)$

Next we substitute (14) to (13) to obtain manufacturer maximum profit $\Psi_{m_{1}}(\max )=u K-\frac{\gamma_{1}}{8 m^{2} K} A^{2} ; \gamma_{1}<0$ with $A=\left(C_{r}+C_{p}+C_{m}+\frac{\gamma_{0} m K}{\gamma_{1}}\right)$. The profit of Damri can be obtain by substituting (14) to (12) to have

$$
p_{1}=\frac{1}{4 m K}\left(C_{r}+C_{p}+C_{m}-\frac{3 \gamma_{0} m K}{\gamma_{1}}\right) \text {. }
$$

Substitute (15) to (8) to obtain $\Psi_{d_{1}}(\max )=-\frac{\gamma_{1}}{16 m^{2} K} A^{2}$ . Analogously, we can find the maximum profit for Damri and manufacturer for the second model. The Damri's maximum profit is given by $\Psi_{d_{2}}(\max )=-\frac{\gamma_{1}}{16 m^{2} K} B^{2}$ with $B=\left(C_{r}+C_{p}+C_{m}+\frac{\gamma_{0} m K}{\gamma_{1}}+\frac{\gamma_{2} u m K}{\gamma_{1}}\right)$ and the manufacturer's maximum profit is $\Psi_{m_{2}}(\max )=-\frac{\gamma_{1}}{8 m^{2} K} B^{2}$.

\subsection{Cooperative Solution}

In cooperative solution, we consider the sum of Damri and manufacturer profit function. For the first subsidy model we have

$\Psi_{1}=\Psi_{d_{1}}+\Psi_{m_{1}}=R_{d_{1}}\left(p_{1}, K\right)-\left(C_{p}+C_{m}+C_{r}\right) n_{1}+u K$

The maximum total profit will be obtained by differentiating this sum with the respect to $p_{1}$, that is $\frac{\partial \Psi_{1}}{\partial p_{1}}=0$ and $\frac{\partial^{2} \Psi_{1}}{\partial p_{1}^{2}}<0$, which yields in

$p_{1}=\frac{1}{2 m K}\left(C_{p}+C_{m}+C_{r}\right)-\frac{\gamma_{0}}{2 \gamma_{1}}$.

By substituting (17) into (16), the maximum total profit of Damri and manufacturer is given by

$\Psi_{1}=u K-\frac{\gamma_{1}}{4 m^{2} K} A^{2}$

Analogously, cooperative solution for the second subsidy model is given by. 
$\Psi_{2}=-\frac{\gamma_{1}}{4 m^{2} K} B^{2}$.

It is straight forward to have the following propositions for these maximum profits.

Proposition 1: In both subsidy model, cooperative solution gives total profit of Damri and manufacturer better than non-cooperative solution $\Psi_{1}-\left(\Psi_{d_{1}}+\Psi_{m_{1}}\right)>0$ and $\Psi_{2}-\left(\Psi_{d_{2}}+\Psi_{m_{2}}\right)>0$.

Proposition 2: The degree of repair and the number of $P M$ that make optimum profit are $\delta=0$ and $N=\sqrt{\frac{K\left(C_{f} K \theta-2 b\right)}{2 a}}-1$ with $N$ is integer. The value $\delta=0$ means Damri does a perfect repair PM.

To illustrate the propositions we give the following numerical example.

\section{Numerical Example}

For example, we have data number of passengers per year $q$, ticket price $p$, and subsidy amount per year $u$ as in Table1.

Table 1. Data number of passengers per year $q$, ticket price $p$, and subsidy amount per year $u$.

\begin{tabular}{ccc}
\hline $\boldsymbol{q}$ & $\boldsymbol{p}$ (in IDR) & $\boldsymbol{u}$ (in $\mathbf{1 0}^{\mathbf{6}}$ IDR ) \\
\hline 1250000 & 3500 & 600 \\
1200000 & 3750 & 550 \\
1190000 & 4000 & 500 \\
1150000 & 4300 & 450 \\
1100000 & 4500 & 400 \\
1000000 & 4800 & 350 \\
920000 & 5000 & 300 \\
860000 & 5500 & 250 \\
820000 & 5700 & 200 \\
700000 & 6000 & 150 \\
\hline
\end{tabular}

Using $R$ application program, we have a linear model for the number of passengers per year $q(p, u)=\gamma_{0}+\gamma_{1} p+\gamma_{2} u$, where $\gamma_{0}=1,975,000$, $\gamma_{1}=-208$ and $\gamma_{2}=0.00006$. If the bus capacity for one year is $m=54,000$ passengers then we have number of buses is $n=\frac{q(p, u)}{54,000}$. Let failure intensity function of bus is Weibull with $\alpha=\sqrt{0,5}$ and $\beta=2$ so the failure intensity function become $\lambda_{0}(t)=4 t$. Cost for every $\mathrm{CM}$ is $C_{f}=I D R 700,000$ and for every PM is $C_{p}^{*}=a+(1-\delta) \tau b$ with $a=I D R 300,000$ and $b=I D R 200,000$. According to proposition 2, we have $\delta=0$ and $N=\sqrt{\frac{K\left(C_{f} K \theta-2 b\right)}{2 a}}-1$ to maximize the profit. The following figures show the result for 3 and 5 years bus operation with D1/2 indicates operator's profit for subsidy model $1 / 2$ and M1/2 indicates manufacturer's profit for subsidy model $1 / 2$.

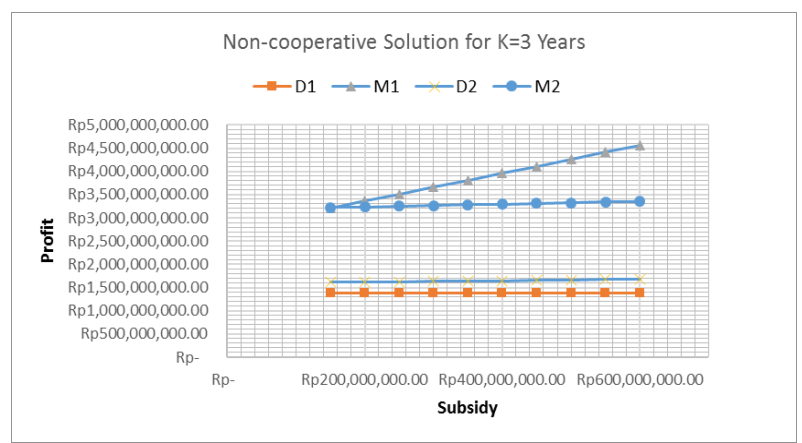

Fig. 1. Non-cooperative solution for 3 years operation.

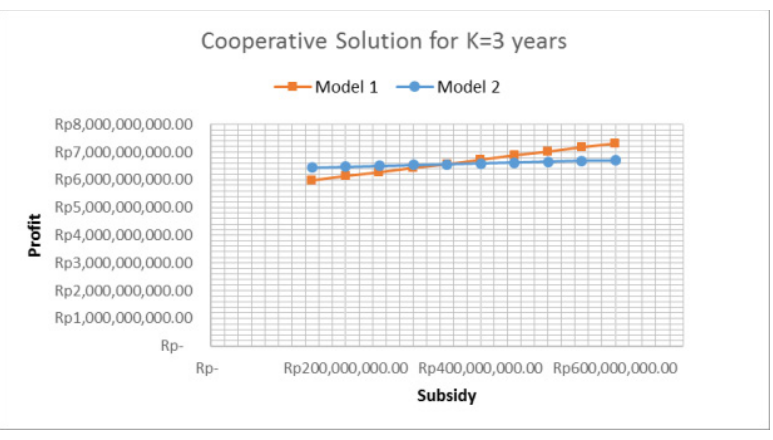

Fig. 2. Cooperative solution for 3 years operation.

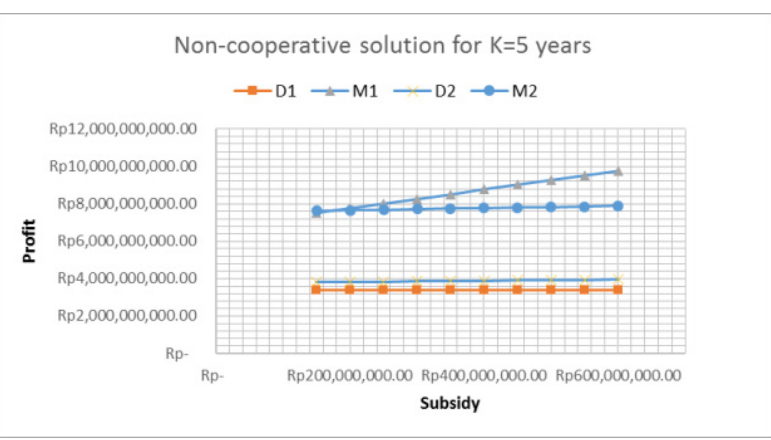

Fig. 3. Non-cooperative solution for 5 years operation.

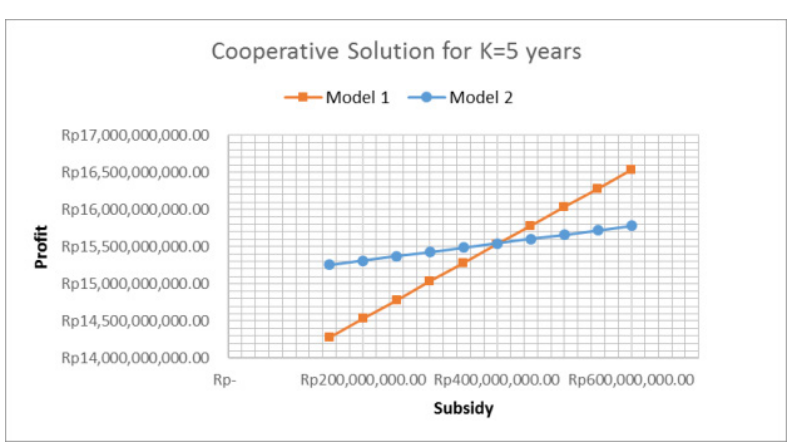

Fig. 4. Cooperative solution for 5 years operation. 
From the examples above, clearly we can see that profit from cooperative solution is higher than non-cooperative. In cooperative solution, when subsidy is getting bigger, the first model is better to use than the second one.

\section{Conclusion}

We have studied two mathematical models of government subsidy to public transportation. In this case we applied the theory to the Indonesian bus public transport agency, i.e. the DAMRI. The subsidy is purported to increase people's interest in using bus for their main transportation. This is done as government attempt to reduce the severity of traffic congestion, which has a damaging effect to the environment. We analysed two different kinds of subsidy: (i) the subsidy in purchasing bus from an appointed public transport manufacturer, and (ii) the subsidy for reimbursing reduced ticket price for passengers. Numerical examples show that:

a) PM reduces the number of failure which makes the buses operating in a longer time of service,

b) Cooperative solution gives a higher profit for both the public transport operator and the manufacturer,

c) From manufacturer point of view, the government subsidy in purchasing bus is better,

d) From public transport operator, the government the subsidy for reimbursing reduced ticket price for passengers is better.

H.H. acknowledges support from Kemenristekdikti for the PUPT research grant contract number SP DIPA/042.06.1.401516/2017 and A.K.S. acknowledges support from Universitas Padjadjaran, due to the funding to parts of this work through the scheme of Academic Leadership Grant (ALG) with contract number 855/UN6.3.1/PL/2017.

\section{References}

1. Hamidi, M., Liao, H., and Szidarovszky, F. (2016). Non-cooperative and cooperative game theoretic models for usage-based lease contracts. European Journal of Operational Research, 4(064).

2. Iskandar, B. P., Husniah, H., and Pasaribu, U. S. (2014). Maintenance service contract for equipment sold with two dimensional warranties. Quality Technology and Quantitative Management, 11(3).
3. Jaturonnatee, J., Murthy, D., and Boondiskulchok, R. (2006). Optional preventive maintenance of leased equipment with corrective minimal repairs. European Journal of Operational Research, 174(1), 201-215.

4. Murthy, D. N. P. and Jack, N. (2016). Game theoretic modelling of service agent warranty fraud. Journal of the Operational Research Society, 68(11).

5. Ross, M. S. (1996). Stochastic Processes second edition. Canada: John Wiley and Sons.

6. Xu, Ying, Zhang, Xuemei and Hong, Yu. (2016). The game model between government subsidies act and green supply chain. International Journal of $u$ - and e-Service, Science and Technology, 9(11), 121-130.

7. https://www.theguardian.com/environment/2008/oct / 29/climatechange-endangeredhabitats

8. http://www.undp.org/content/undp/en/home/sustain able-development-goals/goal-12-responsibleconsumption-and-production.html

9. Myers, N.; Kent, J. (2001). Perverse subsidies: how tax dollars can undercut the environment and the economy. Washington, DC: Island Press. ISBN 155963-835-4.

10. Collins Dictionary of Economics". Retrieved 201309-05.

11. https://en.wikipedia.org/wiki/Subsidy

12. R. Jacksons (1975). Optimal subsidies for public transit, Journal of Transport Economics and Policy, 9(1).

13. Feifei Qin, F and Zhang, Xiaoning (2015). Designing an Optimal Subsidy Scheme to Reduce Emissions for a Competitive Urban Transport Market. Sustainability 2015, 7, 11933-11948; doi:10.3390/su70911933.

14. Ian W.H. Parry Kenneth A. Small (2009). Should Urban Transit Subsidies Be Reduced? American Economic Review 99(3), 2009.

15. Here's How The Government Should Be Subsidizing Public Transit

16. David Levinson and David King Apr. 22, 2013, 12:11 PM (Bussines insider) http://www.businessinsider.com/the-right-way-tosubsidize-public-transit-2013-4/?IR=T 